\title{
Amelina Correa Ramón. “Qué mandáis hacer de mí?": Una historia desvelada de relecturas teresianas en el contexto cultural de entresiglos. Madrid/Frankfurt am Main: Iberoamericana/ Vervuert, 2019, 278 páginas
}

Jorge Chen Sham

Chen Sham, J. (2021). Amelina Correa Ramón. “QQué mandáis hacer de mí?”: Una historia desvelada de relecturas teresianas en el contexto cultural de entresiglos. Madrid/Frankfurt am Main: Iberoamericana/ Vervuert, 2019, 278 páginas. Revista de Filología y Lingüística de la Universidad de Costa Rica, 47(1), e44964. doi: https://doi.org/10.15517/rfl.v47i1.44964

\section{(9) $\mathbb{P Q \Theta \Theta}$}

Doi: https://doi.org/10.15517/rfl.v47i1.44964

URL: https://revistas.ucr.ac.cr/index.php/filyling/index 


\title{
Reseñas
}

Amelina Correa Ramón. "QQué mandáis hacer de mí?": Una historia desvelada de relecturas teresianas en el contexto cultural de entresiglos. Madrid/Frankfurt am Main: Iberoamericana/

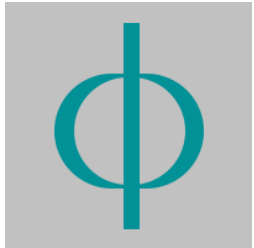
Vervuert, 2019, 278 páginas

\section{Chen Sham, Jorge}

\author{
(iD) Jorge Chen Sham
}

jorgechsh@yahoo.com

Universidad de Costa Rica San José, Costa Rica

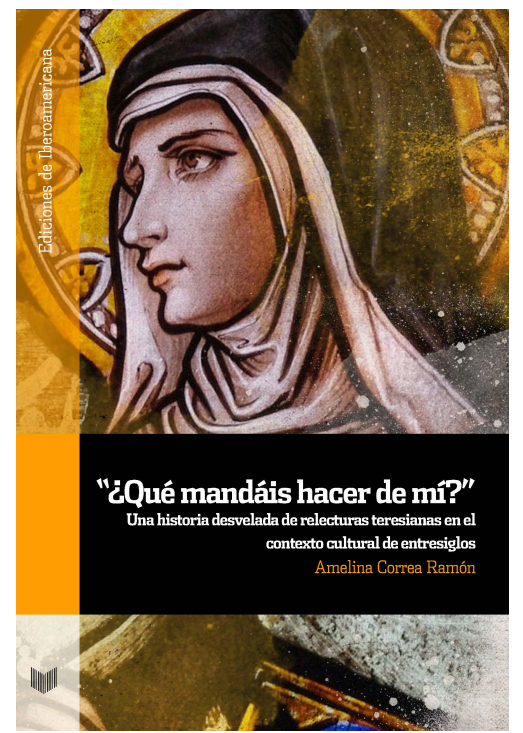

Correa Ramón Amelina. “¿Qué mandáis hacer de mí?”: Una historia desvelada de relecturas teresianas en el contexto cultural de entresiglos. 2019. Madrid/Frankfurt am Main. Iberoamericana/ Vervuert. 278 páginaspp.

Revista de Filología y Lingüística de la Universidad de Costa Rica

Universidad de Costa Rica, Costa Rica

ISSN: 0377-628X

ISSN-e: 2215-2628

Periodicidad: Semestral

vol. 47, núm. 1,2021

filyling@gmail.com

URL: http://portal.amelica.org/ameli, jatsRepo/125/1251597039/index.htm

DOI: https://doi.org/10.15517/rfl.v47i1.44964 
El título del libro reproduce el estribillo de un poema de Santa Teresa de Jesús “¿Qué mandáis hacer de mí?" con ese claro gesto de obediencia que encierra la captatio benevolentiae dentro del discurso místico. Por su parte, Amelina Correa Ramón lo inserta como acápite también en lo que ya no es propiamente un epígrafe por lo voluminoso que es (cinco estrofas). El libro no inicia con una introducción o un prólogo, por lo que el lector no puede contextualizar estos versos y su importancia capital para la propuesta de la autora, porque en tanto ejercicio de apertura comienza con un "Introito: "Vida dulce, sol sin velo". Teresa de Jesús releída como síntoma, ícono o paradigma femenino en el periodo de entresiglos" (11-62), que, por su extensión o sentido, rebasa una introducción y no puede tomarse como propuesta preliminar. Sin embrago, el "Introito: "Vida dulce, sol sin velo". Teresa de Jesús releída como síntoma, ícono o paradigma femenino en el periodo de entresiglos" (11-62), es fascinante y bien documentado. Permite establecer como el título indica una historia de la recepción de Teresa de Jesús (sin el "santo") en un periodo de profundas transformaciones estético-literarias en el mundo occidental. El "fervor y la pasión por la Doctora Mística experimentarán un innegable y casi paroxístico momento de auge" (17), provocado por las efemérides, entre 1882 (tercer centenario de la muerte) y 1922 (tercer centenario de su canonización). Los homenajes, así como las revisiones y las recreaciones literarias y críticas se suceden para proponerla "como modelo femenino y ejemplo de espiritualidad” (18). Como es obvio, Amelina Correa Ramón comienza por detallar las exposiciones y las celebraciones públicas en forma de florilegios, panegíricos, declamaciones, que forman parte de la conmemoración pública, para terminar con las nuevas ediciones de su obra, al llegar el tercer centenario de su elevación a los altares. Predominan aquí la expresión laudativa y epidíctica de la figura de santidad de la monja, "representante del espíritu encendido por el amor de Dios y la entrega religiosa" (21); modelo religioso que también inspiró en los casos de Edith Stein y Teresita de Lisieux.

Mención aparte merece el vínculo místico y los atributos psicológicos, que forman parte de esta recuperación de la dicotomía mujer / santa y que están vinculados a la psicopatología y los estudios precursores sobre la sexualidad (29), en donde el caso de la monja se analiza como "síntoma amenazante, como riesgo potencial que puede llevar a aquellas mujeres que intenten imitarla a despeñarse por la senda de la histeria y la neurosis" (29), eso sí, dentro de esa dicotomía alma / cuerpo que busca conectar visiones místicas con crisis nerviosas. Amelina Correa Ramón subraya ese imaginario dicotómico sobre el cual se concibe a la mujer: dócil / rebelde, virgen / madre, María / Eva, pura / promiscua, el cual posibilita esas interpretaciones un poco disímiles entre la sublime mística y la locura de sus ansias. Intervendrán aquí tanto el positivismo científico como el psico-biologismo que explicarán los arrebatos místicos "como sublimación de una carencia" (30) y terminarán por diagnosticar estos arrebatos como estados de catalepsia, de ataques, alucinaciones y convulsiones, los cuales el neurólogo francés Jean-Martin Charcot relacionó con la histeria. Se trata de una "feminidad" que la mirada médica controla y aísla para domesticar también la subjetividad de la mujer, como sucede en la biografía de Edmond Cazal (1921), en donde Teresa de Jesús aparece "como un mero cuerpo guiado por instintos, deseos y necesidades" (37). Complementario a lo anterior, José Ortega y Gasset plantea en sus Estudios sobre el amor, la equivalencia y la asimilación entre misticismo, hipnosis y enamoramiento, lo cual da lugar a que Amelina Correa Ramón aborde las "señales de alerta" (39) de que su caso produzca contagios perniciosos; su ejemplo más conspicuo será el personaje de Ana Ozores en $L a$ Regenta, porque, procurando leer los escritos de la monja, quiera imitarla ante un excesivo fervor que es "insano", porque produce quimeras en esa influencia de la lectura en tanto acto quijotesco.

El capítulo más extenso del libro “'Dad tiniebla o claro día'. Amalia Domingo Soler (1835-1909) y la difusión de la Virgen de Ávila en las mesas parlantes” (63-196), se interesa en ese mundo de crisis y de cuestionamiento de la fe científica ante la crisis espiritual en el periodo de entresiglos. Retomando al escritor Joris-Karl Huysmans, la sensibilidad mística o espiritual conduce a los "hiperestésicos artistas" (64) hacia el ocultismo y otros saberes esotéricos, sensualistas o espiritistas, cuya forma más conspicua es la búsqueda de espiritualidad y la libertad imaginativa. La escritora Amalia Domingo Soler, espiritista, contribuirá a la 
revisión de Teresa de Jesús en un contexto en que, con pretensiones científicas, se compruebe la vida post mortem y la comunicación con los espíritus (67). A ello contribuyen profusamente los llamados "gabinetes espiritistas"; Correa Ramón desarrolla el pensamiento de Allan Kardec, cuyo impacto más ostensible se visualiza en las "mesas parlantes" alrededor de las cuales los espíritus eran convocados y se confiaban a los seres humanos (71). Sus ideas las sintetiza en El libro de los espiritus (1857) y atrajo a muchas personalidades del mundo de la cultura, la política y la educación como seguidores convencidos, a pesar de la oposición de la Iglesia Católica. Sus ideas se expandieron rápidamente creando revistas y grupos, para que, con la seducción y con la curiosidad por las cosas de ultratumba y del más allá, también se desarrollaran en el ensayismo y en la literatura y se reconocieran en figuras de la cultura universal su raigambre espiritista y sus dotes paranormales, para que "Mozart, Galileo, incluso, Jesucristo, se convirtieran en interlocutores habituales de las mesas parlantes” (77), al mismo tiempo que la ceguera o los problemas de visión se convirtieron, en su defecto, en un signo de clarividencia, al estilo tanto de figuras históricas como Homero o Milton, o literarias como los videntes Tiresias y Max de la Estrella. Amalia Domingo Soler (1835-1909) representa un caso excepcional dentro del concierto espiritista internacional, pues ella encarnó una figura de autoridad en sus círculos, al tiempo que se ganó un lugar en el ambiente de las letras de veladas y tertulias literarias alrededor de los años 1867 y 1868 (101). Su interés por las apariciones marianas la lleva a estudiar la devoción de la Virgen de la Misericordia, patrona de Reus (104) y a escribir unos relatos espiritistas para la prensa periódica (105), en los que lo numinoso y lo sobrenatural deben aceptarse sin vacilaciones a través de la incorporación de lo confesional o testimonial (106). Amelina Correa Ramón desarrolla la relación entre espiritismo y feminismo a la luz de las colaboraciones de Amalia Domingo Soler con la revista La luz delporvenir, Semanario espiritista, de Barcelona, consagrada en forma especial al público femenino (125) y con una abrumadora presencia de escritoras y médiums mujeres, cuyas reivindicaciones y escritos se extendieron también hacia el terreno del sufragio y de los derechos civiles (127), con esa convicción de parte de Amalia por "enfrentar a los prejuicios establecidos y a los encorsetados moldes en que la sociedad encerraba a las mujeres en la época” (133). De esta escritora, Correa Ramón se dedica a estudiar su autobiografía ;Te perdono! Memorias de un espíritu, "la más peculiar relectura teresiana que nos brinda el fértil pero convulso fin de siglo" (123). Pero antes de ir a la autobiografía, Correa Ramón establece el escenario espíritu con ese triple protagonismo de sus revelaciones: el médium parlante Eudaldo Pagés, la entidad que habla en la persona de Santa Teresa y la transcriptora al papel de las revelaciones, la infatigable Amalia (157), sus sesiones se extenderán por "casi dos años y medio, hasta mediados de 1899” (159), en un casa del Barrio de Gracia, para atracción de devotos y curiosos, con esa noticia de que "el médium Eudaldo había estado supuestamente poseído por un espíritu que había estado, a su vez, en vida, poseída por el arrebato místico" (159, la cursiva es del texto). Amalia publicará en forma paulatina en la revista La luz del porvenir (161), del 18 de febrero de 1897 al 23 de noviembre de 1899, cuando abruptamente pone un apéndice y se cierra la publicación. Ahora bien, es a partir del 24 de agosto de 1899 cuando se consigna al espíritu teresiano; de hecho, el nombre de la comunicante se revela (162). La monja carmelita surge como figura "heterodoxa y transgresora" (158) y Correa Ramón establece unas relaciones con el Libro de la vida y su poesía en una comparación analítica pertinente y bien descriptiva del poderoso influjo de los escritos teresianos por más de treinta páginas de análisis, que es imposible desarrollar con satisfacción en una reseña.

Cierra el libro dos breves capítulos. El primero, con el título “'Sea viña fructuosa'. José Blanco Coris (1862-1946) o la voz distinta de Santa Teresa” (197-224), desemboca en el realce de la figura de este malagueño, pintor, dibujante y periodista, cuya amistad con el poeta Salvador Rueda engalana el ambiente malagueño de principios del siglo XX, abierto a las expresiones modernas del arte y la literatura. Pero el interés por Blanco Coris es su vocación espiritista, que fijó en narraciones breves que escribió con el título de Flor de luz (colección de dictados medianímicos), de 1912, abordando estas experiencias, aunque su línea más significativa la representen sus amplios ensayos Por qué soy espiritista: Estudio crítico doctrinal sobre la sugestión y el espiritismo (1916), Santa Teresa, médium (1920), Cómo se habla a los muertos: manual práctico 
(1925). Todo el amplio excurso que Amelina Correa Ramón realizaba por la cultura espírita finisecular permite justificar este "eslabón que engarza la cadena de heterodoxas lecturas teresianas" (212), para que la mística se convirtiera en una constante en su vida y en sus escritos dentro de una doble dirección: la mística logra el estatuto de médium y, a su vez, necesita uno "para que su espíritu pueda por fin transmitir la verdad quintaesenciada" (218), en una suerte de almas gemelas hermanadas por sus dones y por su "refinada vocación". No es de extrañar que el vínculo se establezca entre mediumnidad y mística, cuya patología psíquica se describe por los estados fisiológicos anómalos y extraordinarios, de trances y de éxtasis (219), así como de revelaciones e iluminaciones. El segundo capítulo, “Morir quiero trabajando'. Padre Eusebio del Niño Jesús (1888-1936). Entre la reivindicación de la ortodoxia y la abstracción del abismo" (225-251), comienza señalando este periodo finisecular en su doble complejidad de "exaltación hagiográfica y de relectura heterodoxa" (225), para que la modernidad científica o la artística fueran condenadas oficialmente por la Iglesia Católica, alertando sobre los peligros y los errores que arrastran a la humanidad a su debacle y destrucción; mientras otros, procuraban una reflexión en síntonía con un cristianismo primitivo y la necesidad de vivir sencillamente la experiencia de fe, de cuya espiritualidad se hace eco también el espiritismo, que "profesa una firme fe en un Dios creador" (228), de búsqueda de la pureza cristiana y revivir el evangelio primitivo. El padre Eusebio del Niño Jesús se une a este debate impugnando la versión heterodoxa y espiritista de Teresa de Jesús. Entre 1918 y 1927, el carmelita se traslada a Cuba, en donde ejerce labores de párroco y escribe obras de devoción y hagiográficas. En el contexto de las efemérides de 1922, sus superiores le encargan labores de difusión de las celebraciones y de reunir documentos y libros para esta ocasión, con lo cual se topa con el libro de Coris Blanco y reaccionará a él "llevado de un efusivo empeño de limpiar el nombre de Teresa de Jesús de lo que le parecen infames sospechas" (240), de heterodoxia y de atrevida disidencia teológica. Su libro San Teresa y el espiritismo, comenzado en la Isla, saldrá en dos volúmenes, dedicados a la Mediumnidad teresiana (1929) y a los Puntos cardinales del espiritismo (1930), respectivamente. Al padre Eusebio del Niño Jesús, estas teorías le merecen todo su rechazo al relacionar a Teresa como espíritu que se manifiesta en sesiones mediúmnicas y condena sus propuestas de análisis de los procesos fisiológicos tales como histerismo, catalepsia, neurosis, erotomanía (243).

En conclusión, un libro ameno y bien documentado, de cuyo proceso sale la figura teresiana dentro de un complejo retrato que sigue seduciendo a los devotos cristianos, también espiritistas, pero sobre todo a los lectores que buscan refugio interior o elevación mística a través de su prosa o de su poesía. 